\title{
O CÓDIGO DAS RUÍNAS
}

\section{CODE OF THE RUINS}

Paola Resende*

RESUMO: Este artigo tem como objetivo discutir a construção da categoria do espaço no livro Código de Minas, de Affonso Ávila. $\mathrm{O}$ artigo parte da identificação de três espaços que constroem a obra: o espaço físico, o espaço cultural e o espaço da página para mostrar como a imbricação dessas três modalidades é um dos aspectos centrais do Código. Por meio da leitura sistemática de poemas, pretende-se demonstrar quais sáo os mecanismos da elaboração dos espaços dentro do livro. Para tal, serão evidenciados os aspectos poéticos e também os aspectos políticos da obra, já que, como nos adverte o próprio Ávila, no prefácio do livro "Poesia e história nunca farão mal a ninguém.".

PALAVRAS-CHAVE: Poesia brasileira; Affonso Ávila; espaço.
* resende.paola@gmail.com

Mestranda em Literatura Brasileira pelo programa de Pós-graduação Estudos Literários da Universidade Federal de Minas Gerais.

ABSTRACT: This paper aims to discuss the concept of space in Affonso Ávila's Código de Minas. There are at least three main connotations for the word "space" which may be considered as structural in that book: the physical space, the cultural space and the specific space of the page itself. This study also focusses on how the imbrication of these three kinds of space provides a meaningful context to Código de Minas. Through the analysis of poems, it is possible to observe several ways by which the space is taken as a complex theme or motive. Besides poetical procedures, political issues and historic references are also highlighted, since, as the author says in the preface to Código de highlighted, since, as the author says in the preface to Código de

KEYWORDS: Brazilian poetry; Affonso Ávila; space 
o onde os da ruína

Affonso Ávila

1. A primeira parte ("Frases feitas") é publicada anteriormente em 1963, livro é finalizado e é publicado em 1969, com "supressões parciais ou integrais de poemas" (ÁVILA, 1997,

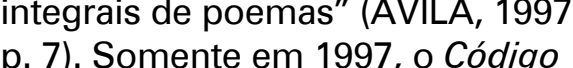
ganha uma nova edição "integral".

A crítica que se debruça sobre o Código de Minas ${ }^{1}$, publicado em 1969, de Affonso Ávila, muitas vezes, ressalta o caráter histórico do livro, colocando em foco seu movimento de retorno ao passado, sem deixar de evidenciar, por meio dele, uma leitura do presente. Entretanto, o aspecto histórico não age sozinho na elaboração desse Código, ele divide a cena com a centralidade da construção do espaço. O espaço, na verdade, são os espaços, pois existe nesse livro o encadea mento de três âmbitos distintos: as Minas Gerais figuradas por espaços físicos e as Minas Gerais figuradas por espaços psicológicos - ou como José Miguel Wisnik apontou lendo Drummond na chave da mineração: "a geografia física e humana” (WISNIK, 2019, p. 27) das Minas Gerais. Esses dois espaços formando "o grande corpo das Minas Gerais”, da epígrafe do livro, colhida em Cláudio Manoel da Costa, que é comentada por Ávila, em uma entrevista 1997, na ocasião da nova publicação do Código:

A epígrafe de Cláudio Manoel da Costa é de uma atualidade extraordinária. Esse corpo informe, cheio de cicatrizes, ao mesmo tempo cheio de marcas, de riquezas, angústias, descobertas, alegrias, decrepitudes e perenidades. Um grande corpo. O rosto de minas, com seus olhos e suas bocas, também um pouco das Minas com suas pernas trôpegas e às vezes com suas pernas mais firmes. (ÁVILA, 2004, p. 15)

Além desses dois espaços, existe um terceiro: o espaço da página, que é explorado por meio da disposição dos versos e das estrofes. Há uma relação entre a estrutura - a organização do verso - e a criação de uma visualidade no poema Essa operação se mostra, em seu horizonte histórico, além de inovadora, como uma tentativa de se aproximar das mudanças ocorridas em seu tempo:

A poesia aqui já não se comporta em suas dimensões tradicionais. Numa época de prevalência da técnica de visualização e, portanto, favorável à disseminação de novos veículos de divulgação da arte, a poesia adquire um outro plano comunicativo e já não se restringe ao consumo na fruição auditiva e na leitura em recolhimento. É a poesia não só para livros, mas para cartazes, os murais, a televisão, a poesia que deseja responder às solicitações de uma civilização coletivista. (ÁVILA, 2008, p. 117)

Benedito Nunes, analisando o livro Cantaria barroca, comenta a proximidade estabelecida entre a palavra e a imagem, desenhando e "redesenhando" o poema: 
O sentido lúdico da poesia junta-se à propensão da visualidade gráfica na leitura; por essa maneira dificultada e desacelerada, o texto, em muitos casos, é redesenhado como documento-monumento, como se não fosse escrito no papel, mas inscrito na pedra de cantaria. (NUNES, 2008, p. 28)

O artifício técnico de construção poética utilizado faz referência às experiências realizadas com a unidade do verso, movimento que toma corpo no Brasil por meio da Poesia Concreta, na década de 50. Ávila, embora não participe diretamente do grupo, mostrava-se próximo das ideias e da intenção em romper com os "tradicionalismos" (ÁVILA 2011, p. 56), temática que foi desenvolvida na criação da revista Tendência. $\mathrm{Na}$ perspectiva do poeta, o marco de aproximação foi o Congresso de Assis, em 1961:

O contato com os "concretos" em Assis assinalaria o início efetivo do "diálogo Tendência-concretismo". Já na verdade existia entre nós - o poeta de Tendência - e os paulistas uma amizade implícita desde a década de 50, quando trocávamos com mútuo interesse os nossos primeiros livros: o "Carrossel", do Décio, "O rei menos o reino", do Augusto, o "Auto do possesso", do Haroldo, o nosso "O açude”. (ÁVILA 2011, p. 54)

No livro em questão, o espaço físico é disponibilizado por meio das referências extratextua is concretas, como os nomes das cidades, os nomes das serras/morros, os nomes dos ribeirões, os nomes das formações rochosas, os nomes das dependências estatais, entre outras. Já o cha mado espaço psicológico é ta mbém acessado por meio de referências extratextuais, mas essas referências são agora abstratas. É o acesso a toda uma estrutura de pensamento e de concepção de mundo: são as expressões idiomáticas bairristas, os brasões familiares, os nomes políticos de destaque, os poetas mineiros, as ações corriqueiras, os costumes, as heranças, os episódios históricos, as posições dentro da sociedade, a centralidade da religião, entre outros. Esses aspectos culturais são alvos de reprovação, nos termos de Ávila: "O projeto político que tínhamos naquela época era extremamente crítico, pois colocávamos em questão uma série de problemas da estrutura e da mentalidade brasileiras, principalmente da mentalidade mineira" (ÁVILA, 2004, p. 12-13). O sujeito poético percorre espacialmente, e, ta mbém, historica mente, esses dois campos, munido de uma "consciência crítica", mesclando essas referências extratextuais a um trabalho formal da linguagem. Nos termos de Ronald Polito:

Decorrem também da natureza do próprio projeto, ao se propor como alegoria a um só tempo histórica, política (ideológica) e poética de certo espaço e tempo de uma experiência sociocultural nevrálgica para a conformação da atual realidade do país: as Minas. (POLITO, 2006, p. 75) 
A página comporta esses dois espaços, realoca-os dentro de uma perspectiva textual, e constrói, por meio de um aspecto visual, uma configuração diversa para os elementos extratextuais. Essa realocação leva em consideração não só a ficcionalização desses elementos, através de sua recriação pela linguagem, mas ta mbém uma reconfiguração espacial, a través da disposição dos versos e estrofes ao longo da página, modificando, muitas vezes, o arra njo tido como habitual do poema. A página se transforma em um espaço de possibilidades, que é explorado por meio da utilização de tipografias, espaçamentos e deslocamentos distintos, somados à construção de sentido do poema.

Assumindo o espaço como uma categoria determinante no Código de Minas, é possível apontar nele um entrelaçamento entre o debate estético e político. $\mathrm{O}$ emprego desses dois campos propicia um diálogo, e não uma anulação. Eles coexistem e se associam no poema. O resultado é a criação de textos com marcas de posicionamento e engajamento, uma espécie de tomada de partido, que avalia a condição de Minas Gerais - no passado e na atualidade de sua publicação - com uma perspectiva crítica. Para Ávila, essa seria a condição de elaboração de criação artística, a não isenção de nenhum dos dois polos:

Só a palavra propiciará ao nosso poeta uma linguagem que não exclua a perspectiva brasileira, a poesia capaz de exportar-se porquanto semanticamente carregada de uma tensão original, revestida de forma brasileira para o fato humano. (..) Numa antítese brasileira, eu diria que a dramática polaridade sócio-existencial do país subdesenvolvido elide qualquer projeto neutro, qualquer concepção que não traga como núcleo a presença do homem. (ÁVILA, 2006, p. 23. Grifo nosso)

Desde o título, Código de Minas, já é estabelecido esse "nexo da palavra poética com a palavra política" (NUNES, 2008, p. 26), ou, como dito por Ávila, "Quer dizer, o que sobra da minha visão crítica passava para minha visão poética, e vice-versa, uma alimentava a outra." (ÁVILA, 2004, p. 16), o que nos permite a nalisar o título à luz de dois fenômenos: o código a trelado ao campo da linguagem, enquanto uma simbolização, uma criptação ${ }^{2}$ - códigos que cifram, representam e constituem o estado e a cultura de Minas Gerais - e o código a trelado ao campo político, enquanto uma legislação ${ }^{3}$ ou compilação de leis/ normas (o Código de Minas ou Código de Mineração), que possui a finalidade de gerenciar as substâncias minerais do estado. Esse aspecto contextual traz como centralidade o minério no espaço e na história de Minas Gerais, fato que não é desvinculado dos códigos sociais e de linguagem criados e disseminados no estado.
2. Nos termos de Décio Pignatari junto a construção de um repertório comum: "E um sistema preestabo que por convenço representar e transmitir uma mensagem entre a fonte e o ponto de destino" (PIGNATARI, 2002, p. 23).

3. A primeira legislação do Código de Minas é datada de 1937, o 1967 - mesmo ano o terceiro de do livro, “Conclú́da em 1967 toda a seriação do Código, diligenciei então publicá-lo em conjunto." ÁVILA, 1997, p. 8. 
4. Para usar o poema "Poética", de Ricardo Aleixo (ALEIXO, 2018, p. 79).
No recente livro Maquinação do mundo: Drummond e a mineração, José Miguel Wisnik aborda a relevância dos trâmites da mineração em Itabira na obra de Carlos Drummond de Andrade, fator que "repercute surdamente nos escritos" (WISNIK, 2019, p. 17). Duas diferenças contextuais devem ser ressaltadas entre o caso de Ávila e de Drummond (ou entre Vila Rica - embora não seja a única localidade, é a predominante nesse livro e na obra em geral - e Itabira): a primeira é o período de exploração das duas cidades: Vila Rica atinge o auge da exploração ao longo do século XVIII, enqua nto Itabira sofre com essa intensidade a partir do século XX; a segunda é o minério predominante na extração: em Vila Rica, o ouro, em Itabira, o ferro. Entretanto, mesmo apesar das distinções, o fator significativo e unificador é a existência de um "impacto da geologia e da história, acopladas" (WISNIK, 2019, p. 29) que apa rece tanto em Ávila qua nto em Drummond (e, se quiséssemos sair do século XX, é determinante na obra de Cláudio Manoel da Costa), indicando a presença em Minas Gerais de uma certa dicção próxima do espaço e da história por meio da "máquina" da mineração.

\section{CONSTRUIR SOBRE RUINAS}

O último poema, “Circuito histórico" (p. 115), traz no primeiro verso "percorrido o périplo da ruína”, uma espécie de síntese do movimento estabelecido pelo livro: um périplo, uma navegação pelas serras, pelos terras e pelas cidades de Minas, que permitiu identificar uma decadência o que resta e permanece de um outro tempo, as suas ruínas ${ }^{5}$. Essa decadência é também experienciada pelo poema do primeiro ao último verso, o que resulta, no aspecto formal, em um isomorfismo dessa ruína, ou seja, o poema plasma, na sua estrutura formal, essa destruição.

Além do termo "périplo", o sujeito poético utiliza outros termos com sentidos semelhantes ("percurso", "perímetro") colocando em destaque esse movimento, esse trânsito proporcionado pelo livro. A mudança é feita em todos os versos da primeira estrofe, alterando apenas a segunda palavra dele, mantendo o som inicial dos termos, o "p":

percorrido o périplo da ruína

percorrido o percurso da ruína

percorrido o perímetro da ruína

percorrido o percalço da ruína

percorrido o préstito da ruína (ÁVILA, 1997, P.117)

Nessa estrofe, esse mecanismo confere uma reiteração à ideia de um itinerário. O recurso é repetido nas três estrofes seguintes, todas sofrem alteração apenas na segunda palavra do verso, mantendo o restante intacto. Quanto à sonoridade, as palavras modificadas sempre conservam seu
5. A questão da ruína foi abordada em Imperial Debris: on ruins Ann Laura Stoler. O objetivo era: "We sought to identify neither the political aesthetics o ruins

nor the aftermaths o catastrophic destruction, but rather the deeply saturated, less spectacular forms in which colonialisms leave their mark". ("Não buscamos identificar a estética política das ruínas, tampouco os desdobramentos da destruição catastrófica, mas sim as formas profundamente intrínsecas e menos espetaculares com as quais os colonialistas deixam sua marca", STOLER, 2013, p. X. Trad. nossa).
EM TESE
BELO HORIZONTE
v. 25
N. 3
SET.-DEZ. 2019
RESENDE. 0 código das ruínas
P. $30-43$ 
som inicial ("p", "c", "r" e "i”), que é, também, o som inicial da primeira palavra do verso, mantendo um paralelismo na cadência da estrofe.

Há nesse movimento de repetição das estruturas um impedimento da criação de uma linha discursiva. Além disso, esse poema propõe um "Circuito histórico" não elogioso, que destaca não uma perspectiva positiva desse espaço, ma a sua ruína. No campo formal, pela quebra das palavras, constrói-se um poema com aspecto visual ruinoso (isto é cria-se uma imagem que desmorona), plasmando o "périplo da ruína”, tema central do poema. Desse modo, cria-se um isomorfismo, pois, ao tematizar a ruína, o poema ta mbém a estrutura na página. Essa degradação acontece, principalmente, pela decomposição da primeira palavra de cada estrofe e verso, o que demonstra sua corrosão transformando-a em desmoronamento. $\mathrm{O}$ espaço da página é preenchido por uma ruína, assim como o espaço das Minas. Do primeiro ao último verso, a sequência monta a seguinte ordem:

\section{percorrido}

corroído

roído

ido
Para Murilo Mendes, na orelha do Código, na edição de 1997: “.. livro importante, que nos restitui o itinerário vivo de um poeta participante das experiências literárias e sociais do nosso tempo”. O itinerário, proposto pelo poeta, permite percorrer o espaço físico e cultural das Minas Gerais. A aproximação e a recriação, por meio da linguagem, desses espaços parte de uma perspectiva crítica (quase sempre uma desaprovação) que, por meio de, principalmente, arranjos linguísticos e pa ródias, joga com terminologias e histórias recorrentes, para dar-lhes uma outra estrutura de pensamento. Nos termos de Polito:

Em vez de argumentação, a decomposição; em vez de justificativa, o estranhamento. A aparente repetição revela-se assim pura sucessão de rupturas, choques, dissonâncias, trazendo à tona os pontos máximos de uma sequência de elisões de possíveis histórias não contadas, para que cheguemos, a final, ao outro lado talvez mais verdadeiro da realidade (..). A tarefa é explodir, principalmente pela sátira, mas não apenas, o contínuo da linguagem, a consciência auto-referente em sua pequena história, a mesmice das crenças, as formas de dominação vigentes. (POLITO, 2006, p. 79-81)

O movimento é o de destruição ("explosão”), seja da estrutura do poema ou de alguma estrutura social que o 
permeia. Seguindo uma linha de pensamento semelhante, Silviano Santiago assinala que:

E é o jogo entre um elemento e o verso, entre o modelo e o verso, entre o original e a reprodução infiel, que constitui o cerne do choque poético que Affonso Ávila inaugura em cada novo verso. (SANTIAGO, 2006, p. 99)

O Código é, então, regido por choques e tensões, que visam decompor o aspecto discursivo da linguagem, mas também decompor as formas de dominação vigentes, construindo um poema que se articula contra essas duas concepções.

A temática da destruição aparece desde a epígrafe desse último poema, por meio de um sermão proferido em Mariana, em 1745, que faz referência a Virgílio, trazendo a expressão "Ca mpus, ubi, Troia, fruit", que se refere à destruição de Tróia por meio de um incêndio, e o consequente a bandono da cidade. No poema não é só tematizado, mas é ta mbém isomorfizado esse "Circuito histórico", essa "rota da ruína” das Minas Gerais.

No poema "Orografia" os nomes dos "morros" não se apresentam somente como um panorama referencial, que visaria uma alusão ao espaço físico por eles ocupado, eles articulam também uma concepção linguística. A perspectiva não é a de um ponto de vista geológico, como acontece nos estudos orográficos (um mapea mento do "morro"), mas, sim, uma perspectiva de decomposição linguística dos nomes dos morros. Esses termos não são ferramentas referenciais, não há uma subordinação ao mundo extra textual. Sobre esses dados do mundo empírico, Benedito Nunes, citando Ávila, afirma que:

Mas a palavra poética não está subordinada, na condição de meio, de veículo secundário, a um projeto de ação política, que se destinaria a mobilizar; ela é uma "parte do processo de descoberta, de reformulação da realidade", como diria, mais tarde, em agosto de 1963, o Manifesto da Semana Nacional de Poesia de Vanguarda, subscrito de Affonso Ávila. (NUNES, 2008, p. 27)

Enquanto os morros no mundo empírico são decompostos pela mineração (uma espécie de ruína), aspecto evidenciado pela epígrafe: "Os morros descarnados ficam de esqueleto à mostra.” (LATIF apud ÁVILA, 1997, p. 23), o poema decompõe os nomes dos morros em outras palavras. A partir desse procedimento, pode ser identificada uma crítica ao processo da mineração, que retira a "carne" dos morros, deixando-os sulcados, com "esqueleto à mostra", assim como estão as palavras no poema (são "descobertas"): 
6. Para aprofundar a relação existente entre espaço e sociedade ver: $A$ produção do espaço e Espaço olítica, de Henri Lefebvre.
Espinhaço

espinho e aço

espinho e osso

espinho e fosso

espinho ácido

espinho ávido

espinho nosso

O poema põe em destaque esse esqueleto, por meio de uma decomposição ocorrida na linguagem e ta mbém no espaço físico das serras: as palavras e as serras são esfaceladas. Além da decomposição, os versos curtos demonstram a utilização de uma condensação no poema, ferramenta que é comentada por Ávila "Para exprimir o universo de significações e de sugestões condensado nas três unidades lidas [três fragmentos de poemas, sendo um deles de "Orografia], o poeta teria, dentro da forma discursiva tradicional, de utilizar umas boas laudas de papel .." (ÁVILA, 2008, p. 120).

Nesse caso, a presença da mineração afeta tanto o espaço físico dos morros quanto o espaço social por eles circundado: as estrofes não se referem apenas aos morros, mas à sociedade que é mantida em torno deles ${ }^{6}$. Para Rui Mourão, o procedimento parte de um imbricamento:

Essa interação - com tendência a se fundir, se identificar que se observa entre o mote e a glosa, ganha sentido ao se verificar que o primeiro, constituindo-se de um elemento dado, nada mais é do que a própria realidade, questionada, decomposta ou comentada pela segunda - o eu lírico com a sua violenta fome de conhecimento. (MOURÃO, 2006, p. 90)

Os nomes das montanhas mineiras são decompostos em palavras “ácidas”, palavras acusa tórias, que não só demonstram essa corrosão linguística, mas também reforçam um ataque aos exploradores do minério: "comparsas", "canalhas", "corja". Outros termos que aparecem como adjetivos dos morros continuam colocando em evidência seu aspecto negativo: "fosso", "ácido”, "cobra”, "cólera”, "cova”, "castrar", "calar", "morte” entre outros. O "espinho nosso" (último verso da estrofe da serra do "Espinhaço", serra que foi, aliás, a mais afetada com a mineração no período colonial), por meio do uso do pronome possessivo plural expõe uma ideia de proximidade com o espaço que o circunda, é uma relação de posse, mas ta mbém de pertencimento. Além disso, o verso também aponta como as montanhas (e, de certo modo, ta mbém a mineração) são uma questão conflitiva para Minas, seu espinho, isto é, seu ponto vulnerável.

\section{ÍNDICES DA RUÍNA}

No poema "Trilemas da mineiridade", o primeiro do livro, o título joga com a expressão, muito recorrente, "dilemas de", utilizada para dar ênfase a um problema de 
7. Uma tentativa de, talvez, responder à pergunta feita por Guimarães " tantas Minas, porém, e, contudo uma, será o que a determina então, apenas uma atmosfera, sendo o mineiro o homem em estado minasgerais?" determinada temática. A relação no poema não é mais com uma dupla proposição, mas, sim, com uma tripla proposição, com um trilema, que articula em cada terceto um elemento em três relações distintas. Todos os versos possuem um paralelismo pelo uso de anáforas, todos iniciados com "eu em". Esse "eu" está sempre "em" algum outro elemento, e parece que é nessa relação que encontram-se

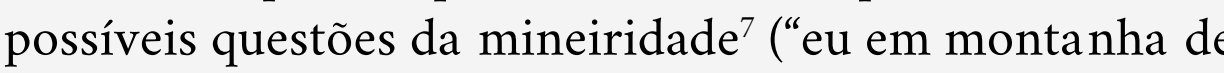
minas”, ÁVILA, 1997, p. 13), embora essas questões sejam construídas por meio de antagonismos e incongruências, nos termos do próprio Ávila "Mineiridade é um paradoxo, sempre foi." (ÁVILA, 2004, p. 16). Na primeira estrofe já é demonstrada, sob dois elementos centrais, os trilemas próprios da mineiridade:

\section{eu em mim}

eu em minas

eu em minas de mim (ÁVILA, 1997, p. 13)

Nessa estrofe, a construção mostra um imbricamento entre dois elementos: o sujeito poético e o espaço. O "eu" e as "Minas" possuem uma relação de proximidade e de pertencimento. O sujeito poético está em si e também está no espaço, nesse caso, as Minas. Além disso, ele ta mbém está na Minas de si, como se espaço exterior tivesse sido interiorizado, por meio de sua subjetividade, é a "minas de mim”, e não qualquer outra Minas.

Esse movimento cria uma espécie de espaço mental mineiro, composto por tradições, costumes e condutas. No poema "Constelação de grandes famílias" (p. 73), a primeira parte, Jogo de cena, traz uma esquema tização de posições familiares - do pai, do filho, do neto - e, por meio de uma gradação, as gerações modificam-se. O jogo leva em consideração cinco datas distintas, nas quais o fundamento da alteração é a mesma: do pai para o neto há uma guinada ideológica, de um pai que mantém uma estrutura violenta e desigual, para um neto que reivindica e age a favor do fim desse sistema.

Desde a capa da edição de 1997, já é demonstrada uma crítica a questão familiar ao trazer as iniciais "TFM", fazendo referência à Tradicional Família Mineira, movimento ao qual Ávila se opôs fortemente: "há uma linha mineira sempre pensando à frente, mas é uma linha minoritária, que sofre uma pressão violenta do conservadorismo mineiro, que é uma praga, uma doença incurável." (ÁVILA 2004, p. 16). Rui Mourão também destaca essa imputação realizada no Código, comentando mais especificamente sobre o poema "Itaversão", mas teorizando um aspecto que é presente em todo o livro: "A luta contra a discursividade e pela objetivação da linguagem surge conjugada com 
o esforço de denúncia de uma realidade ideologicamente esclerosada (..)" (MOURÃO, 2006, p. 95).

Os sextetos que compõem o poema podem ser divididos em duas estruturas: nos primeiros três versos,é exposta uma adjetivação das figuras fa miliares, que varia de acordo com as da tas, enquanto nos últimos três versos há repetição, que gera uma conformidade de atuação mesmo nas datas distintas. A passagem do tempo é identificada pela marcação explícita das datas, mas poderia ser depreendida também pelos cargos e órgãos, que configuram espaços políticos distintos. O efeito é que mesmo intercambiando os adjetivos (e as profissões). Ao final, parece permanecer uma estrutura subjacente, na qual algo sobrevive:

$$
\begin{aligned}
& \text { (pai rouba } \\
& \text { filho come } \\
& \text { neto passa fome) (ÁVILA, 1997, p. 75-76) }
\end{aligned}
$$

Nessa repetição, há uma valoração, que enfatiza, de certa forma, que nessa "constelação familiar" existe uma estrutura previamente demarcada, que sempre fará com que o pai roube, o filho coma e o neto passe fome (estrutura essa que é vinculada à ideologia dos sujeitos). Por meio dessa inserção, a tomada de posição do sujeito poético é crítica ele não se aproxima de modo isento da questão. A realidade é exposta e é lida com um viés de desaprovação: o sujeito poético a taca as operações desse mundo empírico e intenta construir outras operações no lugar:

O poeta trabalha dentro da realidade e dentro da utopia. A utopia, no fundo, é um desdobramento da realidade, como a poesia também é. Acho que Código de Minas é um livro utópico, de certa forma, porque eu queria uma vida muito melhor do que ela é, mas ao mesmo tempo é um livro realista, crítico, porque vê Minas como ela está. (ÁVILA, 2004, p. 17)

Há um outro indício dessa criticidade, no momento em que é omitida a última data, substituída por reticências “..”. Nessa omissão, provavelmente, deveria se encaixar algum ano entre 1963 e 1967 (os anos da composição do livro), demarcando a ainda presença dessa figuração familiar, que é ta mbém política, e, também, uma impossibilidade da realização dessa crítica, devido, depois de 64, à censura. Nessa mesma estrofe, a nomeação de possíveis partidos políticos (PA para o pai, PB para o filho, PC para o neto) é ta mbém marcada pela atmosfera da censura, ao denominar dois partidos políticos não existentes, e um que havia sido extinto em 1945.

No poema "Passagem de Mariana" há um recorte de um "Cartaz de advertência na Rodovia dos Inconfidentes" (p. 43), a epígrafe da seção traz um trecho desse cartaz: 
“DEVAGAR...ATENÇÃO, A 200 M, etc.”. Antes de vira rmos a página, a expectativa é a de que o cartaz esteja advertindo sobre algum aspecto físico, uma barreira física e fixa que ali é localizada, uma descrição do espaço físico, como é a praxe em placas de trânsito. Entretanto, na primeira estrofe do poema (que, no livro, é centralizada), descobrimos que a advertência se refere a uma possível retenção humana (p. 45):

\section{devagar... atenção a $200 \mathrm{~m}$ \\ fiéis saindo \\ da igreja}

O cartaz, com uma linguagem próxima a placas regulares de trânsito, diz sobre um fenômeno específico do espaço mineiro, provavelmente o único estado do país onde se encontraria esse texto disposto em uma rodovia. A rodovia em questão possui o nome popular "Rodovia dos inconfidentes" e passa pelos espaços centrais do livro, Ouro Preto e Mariana, antiga Vila Rica. Além disso, a escolha pelo uso do nome popular da rodovia (ao invés de BR 356/262) reforça outras passagens do livro que realizam referências ao movimento da Inconfidência Mineira (como é o caso dos poetas inconfidentes, no poema "Os insurgentes”, p. 35)
Os eventos em torno da religião e do espaço da igreja possuem uma centralidade cultural no estado, datada ainda da época da colonização. Essa importância persiste até o contexto de publicação. A persistência desse código é ressaltada em outras partes do livro, mas, aqui, na segunda estrofe (que também é centralizada no livro), encontra em dois termos uma solidificação:

\section{devagar... atenção \\ há 200 anos \\ fiéis saindo \\ da igreja}

A mudança do "m" para "anos" não é só uma passagem de uma perspectiva espacial para uma perspectiva temporal (fato que é também corroborado pela mudança da preposição "a" para o verbo "há”), mas ta mbém mostra uma permanência desse espaço dentro de um espectro de tempo. Há 200 anos a mesma cena acontece no mesmo espaço: fiéis saem da igreja. $\mathrm{O}$ espaço psicológico, vinculado à religiosidade, configura uma permanência do espaço físico das igrejas. A manutenção de um costume, e ta mbém de toda uma estrutura de mundo e de pensamento, persiste nas Minas Gerais, como um movimento de continuação de uma tradição. Para Polito: "O que recuperamos é uma 
estratégia de confrontos, um esquema de defesa linguística, um sistema de acintes calculados, sendo o poema construído a partir da desconstrução analítica dos enunciados da memória comum" (POLITO, 2006, p. 81).

O poema "Motetos à feição de Lobo de Mesquita" utiliza uma epígrafe de John Mawe, importante mineralogista que visita o arraial do Tijuco, próximo a Dia mantina no início de século XIX. O tijuco é a localidade que Lobo de Mesquita - compositor, maestro e professor - escolhe para morar. O espaço em comum liga o compositor mineiro ao mineralogista inglês. O poema escrito "à feição" desse compositor parece ser uma espécie de homenagem, que compõe, então, um moteto com referências espaciais à região em que viveu. Cada "passo" traz um elemento que pode ser associado à localidade em questão: "ribeirão do inferno", "portão de ferro", "pedra capistrana", "beco da pena de ouro", "estrela polar", "casa da glória" e "diamantina".

O "passo" que é o "passo gráfico", uma terminologia musical, parece adquirir no poema um duplo sentido, referindo-se também ao deslocamento proporcionado pelo passo do corpo, e que a cada passo chega a um determinado local ("ribeirão do inferno", "beco da pena de ouro", "casa da glória”) ou observa determinado aspecto daquela localidade ("portão de ferro", "pedra capistrana”, "estrela polar"). Os seis primeiros "passos" são todos compostos por uma única palavra, que é decomposta pela primeira voz, recomposta pela segunda voz e repetida pela terceira voz. O sétimo "passo", entretanto, acrescenta entre parênteses uma adjetivação à Diamantina:
dia (afável dia) mantina
dia (arável dia) mantina
dia (amável dia) mantina
diamantina (ÁVILA, 1997 p 79)

Esse último passo confere uma modificação em relação aos passos anteriores: enqua nto estes era m objetivos e compostos apenas por um termo, aquele traz uma subjetividade e insere dentro do termo principal (Dia mantina). É como se essa última parte reunisse todos os elementos anteriores (eles existem espacialmente em Diamantina) e eles ta mbém fossem ressignificados como afáveis, aráveis e a máveis. $\mathrm{O}$ adjetivo "a rável" destoa dos outros dois adjetivos empregados - que pertencem ao campo dos sentimentos, do afeto por pertencer ao campo do cultivo, das ciências naturais. $\mathrm{O}$ termo arável parece estar ali para nos lembrar que, mesmo em um moteto, que aparentemente tem como tema central as peculiaridades e as belezas de uma cidade, saber a utilidade e a rentabilidade desse espaço se faz necessário. 


\section{CONSIDERAÇÕES FINAIS}

O Código de Minas se insere em um debate histórico e geográfico munido não só de uma consciência política, mas também de uma consciência poética, o que concede ao livro operações estéticas que não são desvinculadas de referências políticas, buscando uma proximidade com o mundo empírico - e não o isola mento em relação a ele.

A tentativa de compreensão desse Código não se cumpre somente na esfera cultural, cumpre-se, ta mbém, na esfera poética: a mbos os percursos são permeados pela inovação ou pela mudança do que está posto no mundo empírico e no mundo literário, construindo um caminho que pretende deixar certos aspectos - não todos - no passado, e, no lugar deles, criar e fixar algo novo, seja uma saída em relação ao conservadorismo mineiro ou ao conservadorismo literário. É o trabalho com a realidade e com a utopia que já nos disse o poeta.

A realidade escolhida, "o grande corpo das Minas Gerais", traz impasses árduos de serem decodificados, mas o livro abre caminhos na decifração dos índices que formam esse Código: a permanência de estruturas físicas e simbólicas datadas de duzentos (ou mais) a nos a trás. Essas estruturas são o excesso da moeda e dos bancos, que aparece em "Constelação da usura maior"; a ainda presente corrosão dos morros, que aparece em "Orografia”; a centralidade da religião que permanece há dois séculos, em "Passagem de Mariana”; a cena dos conventos, em "As reclusas de Macaúbas”. A sobrevivência de códigos que já eram impróprios em seu tempo de origem, e, na época da produção do livro, tornam-se não só impróprios, mas ta mbém anacrônicos. Nos termos de Polito:

A Minas cujo código ele se esforçava por decifrar aparece em closeups de corpo inteiro. A Minas que chegou afinal a se explicitar de maneira mais completa e acabada é a Minas entrevada por uma estrutura social por excelência antidinâmica e, por isso mesmo, estacionária e esclerosada, de sorte que o cartaz da "Passagem de Mariana" pode ser válido tanto para hoje quanto para duzentos anos atrás (..). (POLITO, 2006, p. 94)

O livro coloca em destaque a terrível atualidade das disposições, dos dizeres, dos esta tutos, das crenças: o arcabouço cultural parece não ter sido alterado, é como se o espaço das Minas vivesse ainda em outro tempo, ou, ainda, nas ruínas de um outro tempo.

\section{REFERÊNCIAS}

ALEIXO, Ricardo. Pesado demais para a ventania. São Paulo: Todavia, 2018. 
ÁVILA, Affonso. "Affonso Ávila" in OLIVEIRA, Fabrício Marques de. Dez conversas - diálogos com poetas contemporâneos Belo Horizonte: Gutenberg, 2004. p. 12-25.

Código de Minas. Rio de Janeiro: Livraria Sette Letras, 1997.

O poeta e a consciência crítica. São Paulo: Editora Perspectiva, 2008

\section{Homem ao termo: poesia reunida: 1949-2005} Belo Horizonte: Editora UFMG, 2008.

. "Resposta de Affonso Ávila para Haroldo de Campos". Suplemento Literário, Belo Horizonte, p. 20-24 outubro de 2006.

"Trinta anos depois: um depoimento muito pessoal". Pós, Belo Horizonte, v.1, n.2, p. 50-58, nov 2011.

Fortuna crítica de Affonso Ávila. Introdução de Melânia Silva de Aguiar. Belo Horizonte: Secretaria de Estado de Cultura de Minas Gerais; Arquivo Público Mineiro, 2006.
MOURÃO, Rui. "Decifração do código" in: Fortuna crítica de Affonso Ávila. Introdução de Melânia Silva de Aguiar. Belo Horizonte: Secretaria de Estado de Cultura de Minas Gerais; Arquivo Público Mineiro, 2006. p. 85-95.

NUNES, Benedito. "O jogo da poesia" in: ÁVILA, Affonso.

Homem ao termo: poesia reunida: 1949-2005. Belo

Horizonte: Editora UFMG, 2008. p. 25-29.

\section{PIGNATARI, Décio. Informação Linguagem, Comunicação} São Paulo: Ateliê Editorial, 2002.

POLITO, Ronald. "Códice de Pedrarias" in: Fortuna crítica de Affonso Ávila. Introdução de Melânia Silva de Aguiar. Belo Horizonte: Secretaria de Estado de Cultura de Minas Gerais; Arquivo Público Mineiro, 2006. p. 73-84.

SANTIAGO, Silviano. "Ahs! e Silêncio" in: Fortuna crítica de Affonso Ávila. Introdução de Melânia Silva de Aguiar. Belo Horizonte: Secretaria de Estado de Cultura de Minas Gerais: Arquivo Público Mineiro, 2006. p. 96-104.

STOLER, Ann Laura. Imperial debris: on ruins and ruinations. Durham: Duke University Press, 2013.

Recebido em: 29-09-2019 Aceito em: 07-01-2020 